\title{
Relapsing organising pneumonitis in a man with primary biliary cirrhosis, CREST syndrome, and chronic pancreatitis
}

\author{
AG DAVISON, O EPSTEIN
}

From the Brompton Hospital, London, and the Royal Free Hospital, London

We report a relapsing, steroid-responsive, organising pneumonitis, in a man with the CREST syndrome (calcinosis, Raynaud's phenomenon, oesophageal dysfunction, sclerodactyly, and telangiectasia) variant of systemic sclerosis and primary biliary cirrhosis. This pattern of pulmonary disease has not previously been described in systemic sclerosis. The association between primary biliary cirrhosis and the CREST syndrome is well recognised in women ${ }^{1}$ and we report the association in a man.

\section{Case report}

A 58-year-old man, a non-smoking clerical worker, presented in May 1978 with an eight-month history of lethargy, weight loss, and a cough productive of mucoid sputum, and increasing shortness of breath for two months. Raynaud's phenomenon had been present for 36 years. On examination he was ill but apyrexial, dyspnoeic on the slightest exertion, with telangiectasia on his face, crackles in the chest, and splenomegaly. His chest radiograph is shown in figure 1. Sputum and blood cultures were sterile. Serological tests for common respiratory viruses, Mycoplasma pneumoniae, Coxiella burnetti, the psittacosis agent, and Legionella pneumophila gave negative results. His haemoglobin concentration was $15 \cdot 2 \mathrm{~g} / \mathrm{dl}$, white blood count $13.7 \times 10 \%$ (normal differential), ESR $49 \mathrm{~mm}$ in one hour, serum IgM $1192 \mathrm{IU} / \mathrm{ml}$ (normal 58-197), and IgG 200 IU/l (normal 57-172). The serum alkaline phosphatase activity was $1549 \mathrm{IU} / \mathrm{l}$ (normal 50-200), aspartate transferase 33 IU/l (normal 5-17), and $\gamma$-glutamyl transferase $269 \mathrm{IU} / 1$ (normal 5-28). The test for antimitochondrial antibody was strongly positive $(>1 / 40)$ and that for anti-DNA antibody negative. A trephine lung biopsy showed organising pneumonia (fig 2). A liver biopsy specimen was compatible with a diagnosis of primary biliary cirrhosis. Eleven days after starting $50 \mathrm{mg} /$ day of prednisolone he could walk up three flights of stairs and there had been considerable resolution of the radiological shadowing.

Over the next year the dose of prednisolone was gradually reduced to $15 \mathrm{mg}$ on alternate days and treatment continued at this dose until August 1980. Sclerodactyly was noted at this time and he complained of acid regurgitation. A barium swallow showed a dilated oesophagus and diminished peristalsis (a previous one had shown nothing abnormal). The chest radiograph had not changed for

Address for reprint requests: Dr AG Davison, Brompton Hospital, London SW3 6HP.

Accepted 23 August 1982 many months (that is, during maintenance steroid treat ment) and showed only residual shadowing in the lingula Radiographs of the hands showed calcinosis. Liver testsoo continued to show evidence of cholestasis, and endoscopict retrograde cholangiopancreatography performed at this time showed a normal biliary system but an abnormal pan- $\sigma$ creas, with stricturing and irregularity of the main pancrea-을 tic duct in the tail of the pancreas.

The dose of prednisolone was gradually reduced over 7 the next six months, and when he had been having $5 \mathrm{mg}$ on alternate days for three months he developed increasing shortness of breath and lethargy. There was fresh confluento shadowing in the right upper zone. The findings at bron- $\omega$ choscopy were normal. This shadowing rapidly resolved? with an increase in the dose of prednisolone.

\section{Discussion}

Pulmonary disease in systemic sclerosis is usually manifes radiologically as lower-zone shadowing, but confluen $\overrightarrow{\vec{\sigma}}$

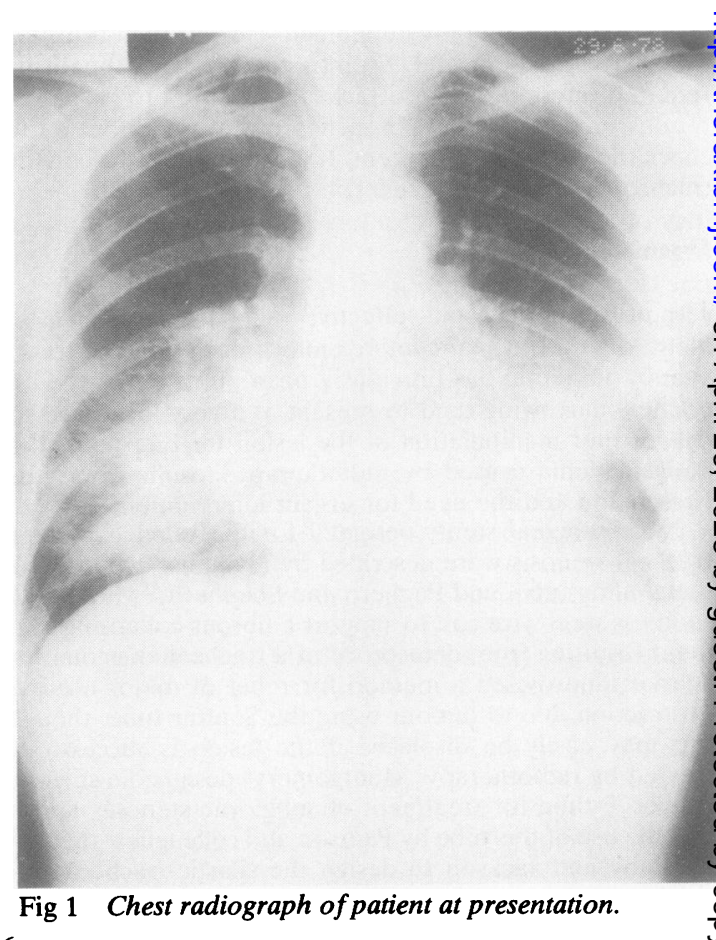




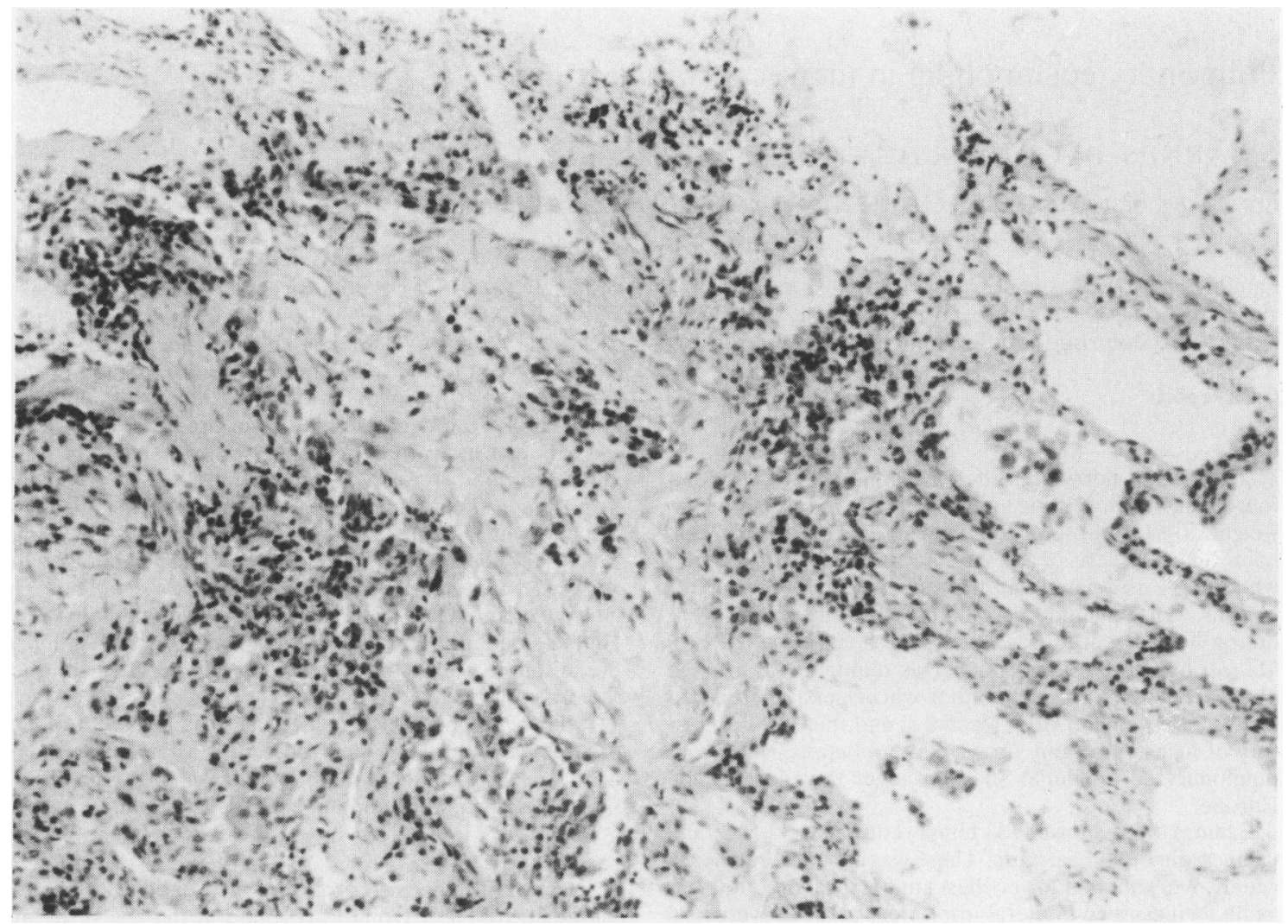

Fig 2 Lung biopsy specimen showing a focus of organising pneumonia with small buds of connective tissue ("bourgeons conjunctifs") in the air spaces and proliferation of fibrous tissue through the pores of Kohn. (Haematoxylin and eosin, $\times 200$.)

shadowing has occasionally been described. ${ }^{2}$ The pathology of the latter has not been defined but in our case an organising pneumonia was found. The aetiology of this is not clear; an organising pneumonia may result from incomplete resolution of infection but no infective agent was identified (and the mode of onset and relapse after three years would not suggest this). Aspiration of gastric acid or contents has been suggested as the cause of the confluent shadowing in systemic sclerosis ${ }^{2}$ but our patient had a barium meal examination showing nothing abnormal at presentation; and the other histological features of aspiration, foreign material, foreign-body multinucleate cells, and extrinsic lipid were absent. ${ }^{3}$ The response to prednisolone, and also the subsequent relapse, was both rapid and dramatic, and similar to that described by Grimblat $e t$ $a l$ in two cases of relapsing organising pneumonias; neither of these, however, had evidence of connective tissue disorders. ${ }^{4}$

In the course of investigating the lung disease, the results of cholestatic liver function tests were noted; a concurrent diagnosis of primary biliary cirrhosis was made and radiographic evidence of chronic pancreatitis was found. The association between systemic sclerosis and primary biliary cirrhosis, although well recognised in women, has been described in only three men, ${ }^{5}$ none of whom had the CREST variant. This case demonstrates the association in a man.

We are grateful to Professor MEH Turner-Warwick, Professor BE Heard, Professor S Sherlock, and Professor PJ Sheuer for their help in the preparation of this paper, and Miss T Chudleigh for secretarial assistance.

\section{References}

${ }^{1}$ Reynolds TB, Denison EK, Frankl HD, Lieberman FL, Peters RL. Primary biliary cirrhosis with scleroderma. Raynaud's phenomenon and telangiectasia. Am J Med 1971;50:302-12.

${ }^{2}$ Gondos B. Roentgen manifestations in progressive systemic sclerosis (diffuse scleroderma). Am J Roentgenol 1960; 84:235-47.

${ }^{3}$ Bulmer SR, Lamb D, McCormack RJM, Walbaum PR. Aetiology of unresolved pneumonia. Thorax 1978;33:307-14.

${ }^{4}$ Grimblat J, Mechlis S, Lewitus Z. Organising pneumonia-like process. Chest 1981;80:259-63.

${ }^{5}$ Douglas JG, Dewhurst NG, Finlayson NDC. Primary biliary cirrhosis and scleroderma occurring in a man. Br J Clin Pract 1981;35:284-5. 